\title{
Mental Health of Persons with Aphasia during the COVID-19 Pandemic: Challenges and Opportunities for Addressing Emotional Distress
}

\author{
Anthony Pak-Hin Kong \\ School of Communication Sciences and Disorders, University of Central Florida, Orlando, USA \\ Email: antkong@ucf.edu
}

How to cite this paper: Kong, A. P.-H. (2021). Mental Health of Persons with Aphasia during the COVID-19 Pandemic: Challenges and Opportunities for Addressing Emotional Distress. Open Journal of Social Sciences, 9, 562-569. https://doi.org/10.4236/jss.2021.95031

Received: April 29, 2021

Accepted: May 22, 2021

Published: May 25, 2021

\begin{abstract}
Aphasia refers to the acquired language deficits, most commonly caused by a stroke, that affect one's verbal understanding, oral expression, reading, and writing. Approximately $31 \%$ of stroke survivors exhibit depression or some depressive symptoms that can impede functional recovery. Since the onset of the COVID-19 pandemic in March 2020, many reports have discussed its psychological and mental impacts on different people worldwide, including both unimpaired individuals and those with chronic illnesses or medical conditions. At present, relatively little has been published on the topic of mental health changes, distress, and/or concerns among persons with aphasia (PWA). Nevertheless, the current evidence reported thus far suggested that PWA had equally suffered from emotional symptoms as a result of the coronavirus outbreak, similar to other disorder populations. With reference to recent reports, the challenges posed to management of aphasia are summarized. Some potential opportunities to address PWA's needs, with an emphasis on their emotional distress, amid and after the pandemic are proposed and discussed.
\end{abstract}

\section{Keywords}

COVID-19, Aphasia, Mental Health, Emotional Distress, Well-Being

\section{Aphasia}

One of the common sequelae of stroke is acquired language deficits, or aphasia. It is a disorder of language functions that negatively and selectively impacts on a person's understanding, speaking, reading, and writing (Worrall et al., 2016), with symptoms manifesting across various levels of performance such as word, 
phrase, sentence, and discourse processing (Kong, 2016). Aphasia is present in approximately $40 \%$ of first-time stroke survivors and can still be found in up to $60 \%$ of survivors in the chronic stage one year post-onset (Engelter et al., 2006). It has also been reported that about $31 \%$ of stroke survivors exhibit depression or depressive symptoms that can impede functional recovery (Hackett \& Pickles, 2014). Other common etiologies of aphasia include dementia, traumatic brain injury, and brain tumors.

\section{COVID-19 and Its Psychological Impacts}

COVID-19 was declared a pandemic on March 11, 2020 (World Health Organization, 2020). At the time this paper was prepared, the world has battled COVID-19 for over 15 months. Many reports have revealed its psychological and mental impacts on different people, including the general elderly population (e.g., Grolli et al., 2021; Meng et al., 2020), children and adolescents (e.g., Saurabh \& Ranjan, 2020), pregnant women (e.g., Rasmussen et al., 2020), teachers (e.g., Stachteas \& Stachteas, 2020), and healthcare workers (e.g., Luo et al., 2020; Tan et al., 2020). Similar studies focusing on specific vulnerable populations have also emerged, such as individuals with dementia (e.g., Keng et al., 2020), Parkinson's disease (e.g., van der Heide et al., 2020), cancer (e.g., Ng et al., 2020), intellectual and developmental disabilities (e.g., Navas et al., 2021), autism spectrum disorders (e.g., Colizzi et al., 2020), neurodevelopmental disorders (e.g., Summers et al., 2021), and caregivers (e.g., Altieri \& Santangelo, 2021; Ng et al., 2020).

These investigations have commonly reported a wide array of psychological consequences provoked by the pandemic-fear, anxiety, depression, stress, indignation, boredom, and helplessness. There were a range of sources that had contributed to these negative feelings, such as prolonged home-stay, concerns for family members and friends, existing health conditions, worry about health and loved ones, quarantine and lockdown measures, disruption of daily life and normal routine, reduction of leisure and social activities, and discrimination. Risk factors that might worsen existing poor psychological well-being included lower socioeconomic status, contraction of COVID-19, lack of up-to-date and accurate COVID-related information, social isolation, reduced peer and family support, and social stigma.

\section{Effects of COVID-19 on Persons with Aphasia}

At present, relatively little has been published on the topic of mental health changes, distress, and/or concerns among persons with aphasia (PWA). Regular social engagement as well as meaningful relationships and activities are important to promote and maintain positive psychosocial well-being in PWA (Bronken et al., 2012). However, the evolving regulatory measures on social distancing in response to the COVID-19 pandemic have broadly disrupted and limited these opportunities. Adoption of new activities or schedules may be needed in some PWA. More critically, the ongoing societal disruptions since its rapid onset more than a year 
ago have posed a huge challenge to conventional face-to-face, facility-based management of aphasia (e.g., speech and language therapy assessment and training sessions, community support group meetings and gatherings) and to PWA's community activities (e.g., leisure peer interactions, recreation and sport activities); these could subsequently lead to difficulties in ensuring a good mood, psychosocial well-being, and quality of life in PWA (Lee, Lee, Choi, \& Pyun, 2015).

One of the very few reports was a recent retrospective interview-based study that investigated how the psychosocial difficulties experienced by Italian PWA have worsened due to COVID-19 (Pisano et al., 2020). A group of 73 chronic PWA previously discharged from rehabilitation services before the COVID-19 emergency were interviewed twice, one month before and one month after the COVID lockdown. With reference to the results of the hospital anxiety and depression scale (Rishi et al., 2017), the PWA demonstrated a significantly higher level of depression and anxiety at the second interview. There was also a significant deterioration in their self-rated quality of life, as reflected by the results of the stroke and aphasia quality of life scale (Hilari et al., 2003). What needs to be highlighted was that the observed negative changes did not vary as a function of factors such as PWA's aphasia severity (mild, moderate, and severe), age, education, or gender, possibly indicating that COVID-19 had equally affected various subgroups of PWA.

Similar findings have been reported by another comparable investigation focusing om chronic PWA residing in Hong Kong (Kong et al., 2020). Specifically, a survey study was conducted to determine whether and how social distancing measures implemented to mitigate COVID spread have impacted PWA's mental health and psychosocial well-being. The adapted scales of psychological well-being (SPWB; Ryff, 1989) was implemented to reflect six dimensions of PWA's mental functioning, including 1) autonomy, 2) purpose in life, 3) environmental mastery, 4) personal growth, 5) positive relations with others, and 6) self-acceptance. Preliminary results based on 15 PWA suggested more distress in the first two dimensions of SPWB in PWA, on top of their higher degree of induced anxiety, depression, and stress than 7 control participants.

In summary, COVID-19 had an elevated risk for exacerbating social isolation and associated negative psychological symptoms in PWA, who inherently are dealing with pre-existing struggles of communication, social, cognitive, and/or intellectual disabilities. As concluded by a recent review article (Kong, 2021), there are still significant knowledge gaps about the short- and long-term impacts of COVID-19 on PWA; this warrants special attention given by different stakeholders to adequately address the psychosocial and rehabilitation needs of PWA during and after the COVID-19 era.

\section{Challenges and Opportunities for Addressing Emotional Distress in Aphasia}

With no doubt, the COVID-19 pandemic has led to dramatic and unprecedent- 
ed changes to many people's life globally. Not only did it pose a threat to public health, but also to how care can be adequately provided when addressing patient needs. The post-COVID-19 era will become different from the world we have known. Thus far, the majority of the literature has discussed how previous and existing social distancing measures have affected PWA in a negative way. However, one must also not neglect the potential disparate opportunities that have created new initiatives for managing aphasia.

Table 1 summarizes how the pandemic can act as a double-edged sword in

Table 1. Challenges and opportunities to address PWA's emotional distress.

\begin{tabular}{|c|c|c|}
\hline & $\begin{array}{l}\text { Challenges amid the pandemic } \\
\text { (Current limitations) }\end{array}$ & Opportunities to improve care of aphasia (Future directions) \\
\hline $\begin{array}{l}\text { 1. Overall } \\
\text { emotional } \\
\text { distress in } \\
\text { PWA }\end{array}$ & $\begin{array}{l}\text { - PWA have experienced various levels of emotional } \\
\text { distress about COVID-19 and its impact on them, their } \\
\text { loved ones, and their communities }\end{array}$ & $\begin{array}{l}\text { - To conduct more research investigations to examine the short- } \\
\text { and long-term effects of COVID-19 on PWA's psychosocial } \\
\text { well-being (Kong, 2021) } \\
\text { - To review and expand existing phone or online outreach } \\
\text { programs or "check-in" services (e.g., Ryan, 2020) to supplement } \\
\text { regular aphasia therapy }\end{array}$ \\
\hline $\begin{array}{l}\text { 2. Telepractice } \\
\text { for PWA }\end{array}$ & $\begin{array}{l}\text { Telehealth for PWA has been around for years but has } \\
\text { not been the most popular option (Kurland, Liu, \& } \\
\text { Stokes, 2018) } \\
\text { - Some PWA might not be able to transition to } \\
\text { teletherapy amid COVID due to digital inequality } \\
\text { (Menger, Morris, \& Salis, 2016) }\end{array}$ & $\begin{array}{l}\text { To continue to advocate and promote the application of } \\
\text { telepractice, with reference to the COVID-related public health } \\
\text { guidance and telehealth policy changes } \\
\text { - To explore application of online programs that treat and prevent } \\
\text { stress-related disorders in PWA (e.g., Weiner et al., 2020) } \\
\text { - To monitor the sudden and unexpected growth of telepractice } \\
\text { during COVID, which may evolve and prompt a new trend of } \\
\text { remote or virtual PWA care in the future }\end{array}$ \\
\hline $\begin{array}{l}\text { 3. Use of } \\
\text { technology }\end{array}$ & $\begin{array}{l}\text { - COVID-19 prompted more PWA to turn to mobile } \\
\text { applications and online resources for conducting } \\
\text { home-based practice } \\
\text { - Available "Aphasia apps" are still limited (Vaezipour, } \\
\text { Campbell, Theodoros, \& Russell, 2020) and } \\
\text { predominantly available in English (National Aphasia } \\
\text { Association, 2015) }\end{array}$ & $\begin{array}{l}\text { To explore the use and effectiveness of digital tools (e.g., } \\
\text { evidence-based websites, smartphone applications, or } \\
\text { conversational agents) by PWA to ameliorate psychological } \\
\text { symptoms (Zhang \& Smith, 2020) } \\
\text { - To develop more aphasia-specific applications in the future } \\
\text { (Vaezipour, Campbell, Theodoros, \& Russell, 2020) } \\
\text { - To develop new and to further refine existing mobile health } \\
\text { applications } \\
\text { To monitor the clinical use of some new initiatives on } \\
\text { family-mediated digital aphasia training }\end{array}$ \\
\hline $\begin{array}{l}\text { 4. Accessible } \\
\text { information } \\
\text { about } \\
\text { COVID-19 }\end{array}$ & $\begin{array}{l}\text { - On average, most current government/official } \\
\text { materials with information about COVID-19 are too } \\
\text { complex for many readers (Hirsch, 2020) } \\
\text { - PWA had limited access to comprehensible and } \\
\text { reliable health information about COVID-19 } \\
\text { - PWA need communicatively accessible (i.e., aphasia } \\
\text { friendly; Rose, Worrall, Hickson, \& Hoffmann, 2011) } \\
\text { written health information about COVID-19 }\end{array}$ & $\begin{array}{l}\text { - To improve and empower PWA to obtain, read, understand, and } \\
\text { use information to make appropriate health decisions (i.e., health } \\
\text { literacy; National Institutes of Health, 2021) }\end{array}$ \\
\hline $\begin{array}{l}\text { 5. Family } \\
\text { support }\end{array}$ & $\begin{array}{l}\text { - Caregivers of PWA assumed multiple important roles } \\
\text { in the rehabilitative process and were overwhelmed } \\
\text { (Shafer, Shafer, \& Haley, 2019) }\end{array}$ & $\begin{array}{l}\text { - To examine and gain a better understanding of psychological } \\
\text { trauma caused by COVID-19 among caregivers of PWA (Sun et } \\
\text { al., 2020; Xiang et al., 2020) }\end{array}$ \\
\hline $\begin{array}{l}\text { 6. PWA } \\
\text { receiving } \\
\text { training at } \\
\text { home }\end{array}$ & $\begin{array}{l}\text { - Home-based intervention was relatively less common } \\
\text { (or unavailable) in the pre-COVID era }\end{array}$ & $\begin{array}{l}\text { - To increase use of virtual clinical visits conducted from PWA's } \\
\text { home, given the convenience to receive therapy (which is also an } \\
\text { incentive that PWA continue with teletherapy; Chiu, 2020) } \\
\text { - To examine if and how PWA respond differently to home-based } \\
\text { therapy, as PWA feel less intimidated in a familiar environment }\end{array}$ \\
\hline
\end{tabular}


aphasia management. Specifically, with reference to recent reports, the challenges posed to management of aphasia (i.e., current limitations caused by COVID-19) are summarized. Some potential opportunities (i.e., future directions to improve care of aphasia) to address PWA's needs, with an emphasis on their emotional distress, amid and after the pandemic are proposed.

\section{Conclusion}

The COVID-19 pandemic has negatively influenced PWA in many ways but, at the same time, provides unique opportunities for robust evaluation of pre-outbreak interventions. Most treatment studies in the literature of Aphasiology have focused on improving the communication aspect. With the psychological implications to PWA, more research is warranted to help us understand the short- and long-term effects of COVID-19 on PWA's psychosocial well-being.

\section{Acknowledgements}

The author would like to express gratitude to the Organizing Committee of The International Congress on Psychiatry (CP 2021) for the invitation to serve as a Keynote Speaker.

\section{Conflicts of Interest}

The author declares no conflicts of interest regarding the publication of this paper.

\section{References}

Altieri, M., \& Santangelo, G. (2021). The Psychological Impact of COVID-19 Pandemic and Lockdown on Caregivers of People with Dementia. The American Journal of Geriatric, 29, 27-34. https://doi.org/10.1016/j.jagp.2020.10.009

Bronken, B. A., Kirkevold, M., Martinsen, R., Wyller, T. B., \& Kvigne, K. (2012). Psychosocial Well-Being in Persons with Aphasia. Nursing Research and Practice, 2012, Article ID: 568242. https://doi.org/10.1155/2012/568242

Chiu, A. (2020). Teletherapy Is Helping Americans Get through the Pandemic. What Happens Afterward?

https://www.washingtonpost.com/lifestyle/wellness/telehealth-teletherapy-mental-healt h-covid/2020/11/12/fdda8776-242c-11eb-952e-0c475972cfc0_story.html

Colizzi, M., Sironi, E., Antonini, F., Ciceri, M. L., Bovo, C., \& Zoccante, L. (2020). Psychosocial and Behavioral Impact of COVID-19 in Autism Spectrum Disorder: An Online Parent Survey. Brain Sciences, 10, 341. https://doi.org/10.3390/brainsci10060341

Engelter, S. T., Gostynski, M., Papa, S., Frei, M., Born, C., Ajdacic-Gross, V. et al. (2006). Epidemiology of Aphasia Attributable to First Ischemic Stroke: Incidence, Severity, Fluency, Etiology, and Thrombolysis. Stroke, 37, 1379-1384. https://doi.org/10.1161/01.STR.0000221815.64093.8c

Grolli, R. E., Mingoti, M., Bertollo, A. G., Luzardo, A. R., Quevedo, J., Réus, G. Z. et al. (2021). Impact of COVID-19 in the Mental Health in Elderly: Psychological and Biological Updates. Molecular Neurobiology, 58, 1905-1916.

https://doi.org/10.1007/s12035-020-02249-x 
Hackett, M. L., \& Pickles, K. (2014). Part I: Frequency of Depression after Stroke: An Updated Systematic Review and Meta-Analysis of Observational Studies. International Journal of Stroke, 9, 1017-1025. https://doi.org/10.1111/ijs.12357

Hilari, K., Byng, S., Lamping, D. L., \& Smith, S. C. (2003). Stroke and Aphasia Quality of Life Scale-39 (SAQOL-39): Evaluation of Acceptability, Reliability, and Validity. Stroke, 34, 1944-1950. https://doi.org/10.1161/01.STR.0000081987.46660.ED

Hirsch, D. (2020). Federal and State Websites Flunk COVID-19 Reading-Level Review. https://news.dartmouth.edu/news/2020/08/federal-and-state-websites-flunk-covid-19-r eading-level-review

Keng, A., Brown, E. E., Rostas, A., Rajji, T. K., Pollock, B. G., Mulsant, B. H. et al. (2020). Effectively Caring for Individuals with Behavioral and Psychological Symptoms of Dementia during the COVID-19 Pandemic. Frontiers in Psychiatry, 11, Article ID: 573367. https://doi.org/10.3389/fpsyt.2020.573367

Kong, A. P. H. (2016). Analysis of Neurogenic Disordered Discourse Production: From Theory to Practice. London: Routledge.

Kong, A. P. H. (2021). The Impact of COVID-19 on Speakers with Aphasia: What Is Currently Known and Missing? Journal of Speech, Language, and Hearing Research, 64, 176-180. https://doi.org/10.1044/2020_JSLHR-20-00371

Kong, A. P. H., Lau, D. K.-Y., Chai, V. N.-Y., Chan, K. P.-Y., \& Sum, K. H.-T. (2020). Understanding the Impact of the COVID-19 Pandemic on the Psychosocial Well-Being among People with Aphasia. Paper Presented at the Academy of Aphasia 58th Annual Meeting, Online, United States.

Kurland, J., Liu, A., \& Stokes, P. (2018). Effects of a Tablet-Based Home Practice Program with Telepractice on Treatment Outcomes in Chronic Aphasia. Journal of Speech, Language, and Hearing Research, 61, 1140-1156. https://doi.org/10.1044/2018_JSLHR-L-17-0277

Lee, H., Lee, Y., Choi, H., \& Pyun, S. B. (2015). Community Integration and Quality of Life in Aphasia after Stroke. Yonsei Medical Journal, 56, 1694-1702. http://dx.doi.org/10.3349/ymj.2015.56.6.1694

Luo, M., Guo, L., Yu, M., Jiang, W., \& Wang, H. (2020). The Psychological and Mental Impact of Coronavirus Disease 2019 (COVID-19) on Medical Staff and General Public-A Systematic Review and Meta-Analysis. Psychiatry Research, 291, Article ID: 113190. https://doi.org/10.1016/j.psychres.2020.113190

Meng, H., Xu, Y., Dai, J., Zhang, Y., Liu, B., \& Yang, H. (2020). Analyze the Psychological Impact of COVID-19 among the Elderly Population in China and Make Corresponding Suggestions. Psychiatry Research, 289, Article ID: 112983.

https://doi.org/10.1016/j.psychres.2020.112983

Menger, F., Morris, J., \& Salis, C. (2016). Aphasia in an Internet Age: Wider Perspectives on Digital Inclusion. Aphasiology, 30, 112-132. https://doi.org/10.1080/02687038.2015.1109050

National Aphasia Association (2015). Aphasia Apps. https://www.aphasia.org/aphasia-resources/aphasia-apps/

National Institutes of Health (2021). Health Literacy. https://www.nih.gov/institutes-nih/nih-office-director/office-communications-public-1 iaison/clear-communication/health-literacy

Navas, P., Amor, A. M., Crespo, M., Wolowiec, Z., \& Verdugo, M. Á. (2021). Supports for People with Intellectual and Developmental Disabilities during the COVID-19 Pandemic from Their Own Perspective. Research in Developmental Disabilities, 108, Article ID: 103813. https://doi.org/10.1016/j.ridd.2020.103813 
Ng, K., Zhou, S., Tan, S. H., Ishak, N., Goh, Z., Chua, Z. Y. et al. (2020). Understanding the Psychological Impact of COVID-19 Pandemic on Patients with Cancer, Their Caregivers, and Health Care Workers in Singapore. JCO Global Oncology, 6, 1494-1509. https://doi.org/10.1200/GO.20.00374

Pisano, F., Giachero, A., Rugiero, C., Calati, M., \& Marangolo, P. (2020). Does COVID-19 Impact Less on Post-Stroke Aphasia? This Is Not the Case. Frontiers in Psychology, 11, Article ID: 564717. https://doi.org/10.3389/fpsyg.2020.564717

Rasmussen, S. A., Smulian, J. C., Lednicky, J. A., Wen, T. S., \& Jamieson, D. J. (2020). Coronavirus Disease 2019 (COVID-19) and Pregnancy: What Obstetricians Need to Know. American Journal of Obstetrics and Gynecology, 222, 415-426. https://doi.org/10.1016/j.ajog.2020.02.017

Rishi, P., Rishi, E., Maitray, A., Agarwal, A., Nair, S., \& Gopalakrishnan, S. (2017). Hospital Anxiety and Depression Scale Assessment of 100 Patients before and after Using Low Vision Care: A Prospective Study in a Tertiary Eye-Care Setting. Indian Journal of Ophthalmology, 65, 1203-1208. https://doi.org/10.4103/ijo.IJO_436_17

Rose, T. A., Worrall, L. E., Hickson, L. M., \& Hoffmann, T. C. (2011). Aphasia Friendly Written Health Information: Content and Design Characteristics. International Journal of Speech-Language Pathology, 13, 335-347.

https://doi.org/10.3109/17549507.2011.560396

Ryan, L. (2020). Health Outreach Project (HOP) Adapts to Providing Care during the Pandemic.

https://drexel.edu/medicine/news-events/news-archive/2020/december/health-outreac h-project-hop-adapts-to-providing-care-during-the-pandemic/

Ryff, C. D. (1989). Happiness Is Everything, or Is It? Explorations on the Meaning of Psychological Well-Being. Journal of Personality and Social Psychology, 57, 1069-1081. https://doi.org/10.1037/0022-3514.57.6.1069

Saurabh, K., \& Ranjan, S. (2020). Compliance and Psychological Impact of Quarantine in Children and Adolescents Due to COVID-19 Pandemic. Indian Journal of Pediatrics, 87, 532-536. https://doi.org/10.1007/s12098-020-03347-3

Shafer, J. S., Shafer, P. R., \& Haley, K. L. (2019). Caregivers Navigating Rehabilitative Care for People with Aphasia after Stroke: A Multi-Lens Perspective. International Journal of Language \& Communication Disorders, 54, 634-644. https://doi.org/10.1111/1460-6984.12467

Stachteas, P., \& Stachteas, C. (2020). The Psychological Impact of the COVID-19 Pandemic on Secondary School Teachers. Psychiatriki, 31, 293-301. https://doi.org/10.22365/jpsych.2020.314.293

Summers, J., Baribeau, D., Mockford, M., Goldhopf, L., Ambrozewicz, P., Szatmari, P. et al. (2021). Supporting Children with Neurodevelopmental Disorders during the COVID-19 Pandemic. Journal of the American Academy of Child and Adolescent Psychiatry, 60, 2-6. https://doi.org/10.1016/j.jaac.2020.09.011

Sun, N., Wei, L., Shi, S., Jiao, D., Song, R., Ma, L. et al. (2020). A Qualitative Study on the Psychological Experience of Caregivers of COVID-19 Patients. American Journal of Infection Control, 48, 592-598. https://doi.org/10.1016/j.ajic.2020.03.018

Tan, B., Chew, N., Lee, G., Jing, M., Goh, Y., Yeo, L. et al. (2020). Psychological Impact of the COVID-19 Pandemic on Health Care Workers in Singapore. Annals of Internal Medicine, 173, 317-320. https://doi.org/10.7326/M20-1083

Vaezipour, A., Campbell, J., Theodoros, D., \& Russell, T. (2020). Mobile Apps for Speech-Language Therapy in Adults with Communication Disorders: Review of Content and Quality. JMIR mHealth and uHealth, 8, e18858. https://doi.org/10.2196/18858 
van der Heide, A., Meinders, M. J., Bloem, B. R., \& Helmich, R. C. (2020). The Impact of the COVID-19 Pandemic on Psychological Distress, Physical Activity, and Symptom Severity in Parkinson's Disease. Journal of Parkinson's Disease, 10, 1355-1364. https://doi.org/10.3233/JPD-202251

Weiner, L., Berna, F., Nourry, N., Severac, F., Vidailhet, P., \& Mengin, A. C. (2020). Efficacy of an Online Cognitive Behavioral Therapy Program Developed for Healthcare Workers during the COVID-19 Pandemic: The REduction of STress (REST) Study Protocol for a Randomized Controlled Trial. Trials, 21, 870.

https://doi.org/10.1186/s13063-020-04772-7

World Health Organization (2020). WHO Director-General's Opening Remarks at the Media Briefing on COVID-19-11 March 2020.

https://www.who.int/dg/speeches/detail/who-director-general-s-opening-remarks-at-t he-media-briefing-on-covid-19---11-march-2020

Worrall, L., Simmons-Mackie, N., Wallace, S. J., Rose, T., Brady, M. C., Kong, A. P. H. et al. (2016). Let's Call It "Aphasia": Rationales for Eliminating the Term "Dysphasia". International Journal of Stroke, 11, 848-851. https://doi.org/10.1177/1747493016654487

Xiang, Y. T., Yang, Y., Li, W., Zhang, L., Zhang, Q., Cheung, T. et al. (2020). Timely Mental Health Care for the 2019 Novel Coronavirus Outbreak Is Urgently Needed. The Lancet Psychiatry, 7, 228-229. https://doi.org/10.1016/S2215-0366(20)30046-8

Zhang, M., \& Smith, H. E. (2020). Digital Tools to Ameliorate Psychological Symptoms Associated with COVID-19: Scoping Review. Journal of Medical Internet Research, 22, e19706. https://doi.org/10.2196/19706 